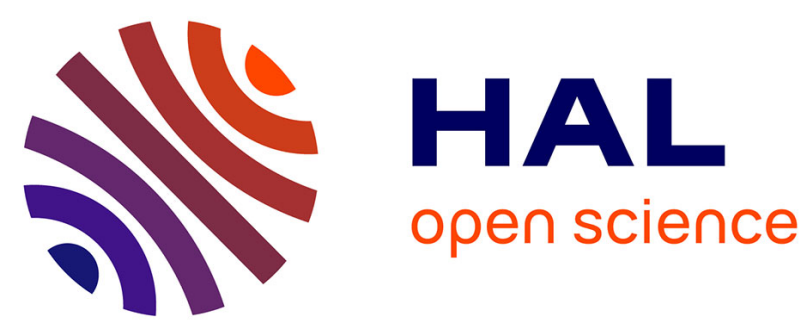

\title{
Distinguishing Galactoside Isomers with Mass Spectrometry and Gas-Phase Infrared Spectroscopy
}

Jordan S Ho, Amira Gharbi, Baptiste Schindler, Oznur Yeni, Richard Brédy, Laurent Legentil, Vincent Ferrières, Laura L Kiessling, Isabelle Compagnon

\section{- To cite this version:}

Jordan S Ho, Amira Gharbi, Baptiste Schindler, Oznur Yeni, Richard Brédy, et al.. Distinguishing Galactoside Isomers with Mass Spectrometry and Gas-Phase Infrared Spectroscopy. Journal of the American Chemical Society, 2021, 143 (28), pp.10509-10513. 10.1021/jacs.0c11919 . hal-03333654

\section{HAL Id: hal-03333654 https://hal.science/hal-03333654}

Submitted on 8 Sep 2021

HAL is a multi-disciplinary open access archive for the deposit and dissemination of scientific research documents, whether they are published or not. The documents may come from teaching and research institutions in France or abroad, or from public or private research centers.
L'archive ouverte pluridisciplinaire $\mathbf{H A L}$, est destinée au dépôt et à la diffusion de documents scientifiques de niveau recherche, publiés ou non, émanant des établissements d'enseignement et de recherche français ou étrangers, des laboratoires publics ou privés. 


\section{Distinguishing Galactoside Isomers with Mass Spectrometry and Gas- Phase Infrared Spectroscopy}

Jordan S. Ho ${ }^{1+}$; Amira Gharbi ${ }^{2+}$; Baptiste Schindler²; Oznur Yeni ${ }^{2}$; Richard Brédy ${ }^{2}$; Laurent Legentil ${ }^{3}$; Vincent Ferrières ${ }^{3}$; Laura L. Kiessling ${ }^{1 *}$; Isabelle Compagnon ${ }^{2 *}$

${ }^{1}$ Department of Chemistry, Massachusetts Institute of Technology, 77 Massachusetts Ave. Cambridge, Massachusetts 02139, United States. ${ }^{2}$ Univ. Lyon, Université Claude Bernard Lyon 1, CNRS, Institut Lumière Matière, F-69622 Villeurbanne, France. ${ }^{3}$ Univ. Rennes, Ecole Nationale Supérieure de Chimie de Rennes, CNRS, UMR 6226 - ISCR, F-35 000 Rennes, France

\section{Supporting Information Placeholder}

ABSTRACT: Sequencing glycans is demanding due to their structural diversity. Compared to mammalian glycans, bacterial glycans pose a steeper challenge because they are constructed from a larger pool of monosaccharide building blocks, including pyranose andf uranose isomers. Though mammalian glycans incorporate only the pyranose form of galactose (Galp), many pathogens, including Mycobacterium tuberculosis and Klebsiella pneumoniae, contain galactofuranose (Galf) residues in their cell envelope. Thus, glycan sequencing would benefit from methods to distinguish between pyranose and furanose isomers of different anomeric configurations. We used infrared multiple photon dissociation (IRMPD) spectroscopy with mass spectrometry (MS-IR) to differentiate between pyranose- and furanose-linked galactose residues. These targets pose a challenge for MS-IR because the saccharides lack basic groups, and galactofuranose residues are highly flexible. We postulated cationic groups that could complex through hydrogen bonding would offer a solution. Here, we present the first MSIR analysis of hexose ammonium adducts. We compared their IR fingerprints with those of lithium adducts. We determined the diagnostic MS-IR signatures of the $\alpha$-and $\beta$-anomers of galactose in furanose and pyranose forms. We also showed these signatures could be applied to disaccharides to assign galactose ring size. Our findings highlight the utility of MS-IR for analyzing the unique substructures that occur in bacterial glycans.

\section{A \\ dvances in mass spectrometry are leading to new} methods to sequence glycans. While MS/MS methods can distinguish some glycan structural features,1-3 their resolution is limited. These limitations are especially apparent in analyzing bacterial glycans, as over 600 different monosaccharide building blocks can be included.4,5 Many monosaccharides in this pool have identical masses and differ only in substituent stereochemistry. Moreover, a single saccharide building block can exist in pyranose and furanose forms, as is the case for galactose. Finally, the regiochemistry of glycan attachment can vary, as can the configuration at the anomeric position. Thus, the challenges of glycan analysis require new analytical methods.6-9 Major advances have been made in microarray methods,10,11 and mass spectrometry-based glycomics. In particular, ion mobility spectrometry (IMS) can be used for upfront separation and structural characterization, and infrared ion spectroscopy of mass-selected ions (MS-IR) provides an additional diagnostic of isomers.8,12-19

The need for advanced methods for glycan analysis is exemplified by the complexity of fully defining a single residue-galactose-within a glycan. Galactose exists in the cyclic five-membered ring furanose and the more common six-membered ring pyranose forms.20,21 Mammals use only the more stable galactopyranose isomer in their glycans; however, the galactofuranose isomer occurs in many microorganisms, including some bacterial species, protozoan parasites, and even multicellular organisms such as nematodes. Numerous organisms generate Galfcontaining glycans, many of which also possess galactopyranose-containing glycans, indicating the importance of accurately distinguishing between different isomers.

Until recently, the means to distinguish between galactopyranose and galactofuranose within a glycan required the application of multiple methods. Nuclear magnetic resonance spectroscopy and vibrational circular dichroism structural analysis in tandem proved to be reliable methods for conformational elucidation of furanose rings.22,23 Alternatively, techniques derived from gas-phase molecular spectroscopy could be used to identify subtle isomeric variations.24,25 More efficient methods, however, are needed to streamline analysis.

MS-IR is a method for glycan analysis that unites tandem mass spectrometry and gas-phase IR spectroscopy.26 In short, a mass spectrometer is modified to allow laser irradiation of $\mathrm{m} / \mathrm{z}$ selected ions. In traditional IR absorption spectroscopy, the transmitted light is measured as a function of the wavelength and the spectrum retrieved using the Beer-Lambert formula. This approach cannot be applied to MS-IR because of the extremely low density of ions. We addressed this issue using an "action spectroscopy" strategy called infrared multiple photon dissociation (IRMPD). In IRMPD, absorption, as a function of wavelength, is detected via the observation of photoinduced fragmentation of the irradiated ions. In general, this hybrid approach has three benefits. First, in a heterogeneous sample, optical signatures are obtained for each analyte after m/z-based separation. Second, the mass spectrometric data is augmented with spectroscopic information, allowing one to 
observe subtle differences between isomers. IRMPD has been broadly used to analyze biomolecular ions,27 and can successfully identify diastereoisomers, 28,29 epimers, 30,31 anomeric configuration, 16,26 ring size,37 and regiochemistry of different saccharides.32,33 Third, in absence of solvent, the $\mathrm{O}-\mathrm{H}$ and $\mathrm{N}-\mathrm{H}$ stretching vibrations are better resolved than in the condensed phase. This spectroscopic technique has the advantages of sensitivity, as only small sample quantities typical of MS are needed and low temperatures are not required.19,34 Thus, in the appropriate wavelength range, the coupling of IR spectroscopy with MS enables the analysis of glycans with identical weight because different isomers will give rise to distinct $\mathrm{O}-\mathrm{H}$ stretch patterns. We postulated that MS-IR could be used to characterize galactose monosaccharide isomers and galactose-containing saccharides.

Distinguishing between galactopyranose and galactofuranose and their anomers is a challenge. Most pyranose sugars have well-defined conformations, but the galactofuranose ring is highly flexible. The lack of rigidity complicates its analysis by spectroscopic methods, including sensitive techniques such as nuclear magnetic resonance spectroscopy.23 Second, these hexoses are not basic; therefore, they do not easily protonate.

Carbohydrates can readily form stable ionic complexes in electrospray ion sources, provided the cations are introduced as salts. For example, $\mathrm{Li}+$ and $\mathrm{Na}+$ adducts of carbohydrates can increase ion signal and sensitivity in mass spectrometry.35 For MS-IR analysis, however, the ion adduct must both promote ionization and enable structural resolution of the spectroscopic fingerprint. Carbohydrate complexation with such $\mathrm{Li}+$ and $\mathrm{Na}^{+}$ can yield IRMPD data with fewer spectroscopic features.28,29 As a rule, protonated ions tend to have more distinct IR fingerprints than alkali adducts. For acidic carbohydrates, the formation of ammonium adducts has been suggested to be an alternative to protonation. 33

To date, MS-IR reports on neutral sugars are scarce and are limited to alkali adducts.26,34,36 For neutral sugars, however, each hydroxyl group is equally basic. We envisioned that ammonium ions could form a bifurcated hydrogen bond network with hydroxyl groups. This interaction should localize the ion to specific sites on the glycan and give rise to a distinct fingerprint. Here we test this hypothesis using a panel of neutral galactose isomers.

To determine whether MS-IR would be effective, we examined four isomers of galactose with fixed ring size and anomeric configuration (Figure 1). Their structures, which were validated by NMR spectroscopy, were designed to assess whether distinctive MS-IR signatures could be obtained. When the four methylated galactose isomers were analyzed, ions were detected at $\mathrm{m} / \mathrm{z} 212$ for the ammonium adducts. Under collision-induced dissociation (CID), fragmentation of the most labile group should occur, which is generally the anomeric substituent. In the case of methyl glycosides, cleavage of the methoxyl group ensues. As a result, the ammonium adducts yielded two main fragments: $\mathrm{m} / \mathrm{z}$ 195, corresponding to the loss of ammonia, and $\mathrm{m} / \mathrm{z} 163$, indicating a release of both methanol and ammonia (Figure S1). Spectra of the $\mathrm{Li}^{+}$adducts showed loss of methanol (Figure S2). Though protonated galactose ions are not produced in the source, they are easily obtained by fragmentation of the ammonium adduct and are detected at $\mathrm{m} / \mathrm{z} 195$ in the MS/MS spectrum of ammonium adducts. This fragment can be re-isolated for further MS/MS study (Figure S3).
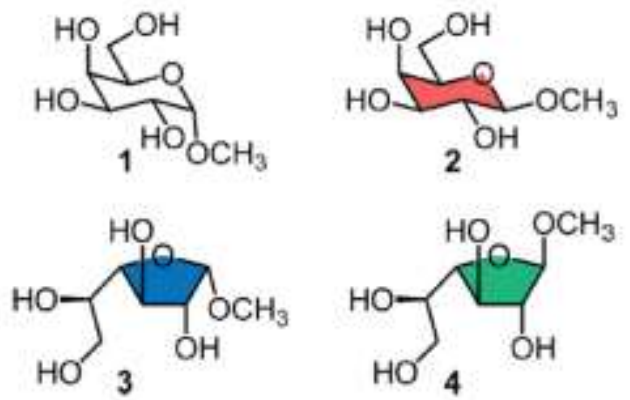

Figure 1. Monosaccharides analyzed by MS-IR methyl-a-Dgalactopyranoside (Galp) 1, methyl- $\beta$-D-Galp 2, methyl- $\alpha$-D-galactofuranoside (Galf) 3, and methyl- $\beta$-D-Galf 4 . Ring coloring corresponds to IRMPD spectra in Figure 2.

Features of the spectra from the ammonium adducts include C-H vibrational activity around $2950 \mathrm{~cm}-1$, intense $\mathrm{N}-\mathrm{H}$ vibrational activity around $3350 \mathrm{~cm}-1$ from the $\mathrm{NH}_{4}$ + moiety, and a resolved hydroxyl group stretch pattern above $3500 \mathrm{~cm}-1$ (Figure 2). For methyl- $\alpha$-D-Galp (1) and methyl- $\beta$-D-Galp (2), this pattern consists of two bands, while methyl- $\alpha$-D-Galf (1) or methyl- $\beta$-D-Galf (2) afforded a single band. The intense peak centered around 3580 $\mathrm{cm}^{-1}$ is visible in both pyranose anomers but absent from either of the furanose spectra. Thus, we could distinguish galactofuranose and galactopyranose isomers.

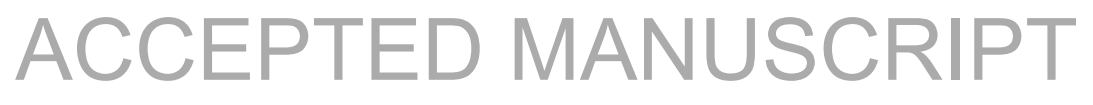




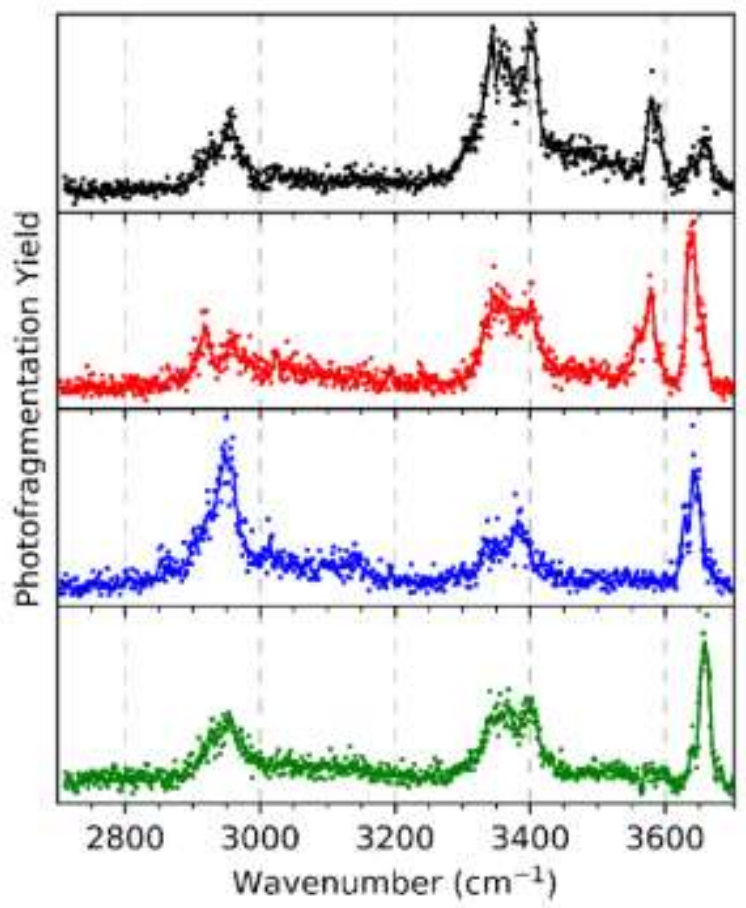

Figure 2. IRMPD spectra of ammonium adducts of isomeric galactosides: methyl-a-D-Galp (1, black), methyl- $\beta$-D-Galp (2, red), methyl- $\alpha$-D-Galf (3, blue), and methyl- $\beta$-D-Galf ( 2 , green).

The ammonium adduct data are less distinguishing of anomers. For galactopyranose, the $\alpha$ - and $\beta$ anomers give rise to distinctive $\mathrm{C}-\mathrm{H}$ bond stretching profiles around $2950 \mathrm{~cm}-1$. Specifically, $\alpha$-Galp 1 gives rise to a single peak centered at $2955 \mathrm{~cm}-1$, whereas $\beta$-anomer 2 affords a more complex spectrum consisting of a doublet at 2914/2955 cm-1, with moderate vibrational activity extending toward $3200 \mathrm{~cm}-1$. For galactofuranose glycosides, the vibrational fingerprints of the $\alpha$ and $\beta$ anomers are similar, yet a slight shift of about $20 \mathrm{~cm}-1$ is visible in the $0-H$ mode: $3640 \mathrm{~cm}-1$ for $\alpha$-Galf 3 and 3660 $\mathrm{cm}-1$ for $\beta$-Galf 4 . The IR signatures of the $\mathrm{Li}+$ adducts are more congested and less distinguishing of the four isomers, yet the minor bands reveal reliable differences between them (Figure S4). The protonated ions did not afford diagnostic spectra (Figure S5).

Although the spectra of the ammonium-galactose adducts of the anomeric isomers were more difficult to interpret, they were diagnostic of ring size. The IR fingerprint of galactopyranose is characterized by an intense $\mathrm{O}-\mathrm{H}$ signal at $3580 \mathrm{~cm}-1$, which is absent from the spectra of galactofuranose. Additionally, although the bands from the lithium adducts show less contrast, they are diagnostic of $\alpha$ and $\beta$ anomers. Thus, different adducts can be used to reveal distinct structural information: the ammonium adducts are diagnostic of the ring size, while the lithium adducts can distinguish stereochemistry.

We used our fingerprint for the monomers to analyze two galactose-containing disaccharides (Figure 3). Specifically, we tested whether the IR fingerprint could distinguish between galactopyranose-containing and galactofuranose-containing disaccharides: $\mathrm{N}$ - acetyllactosamine ( $\beta$-D-Galp-(1,4)-GlcpNAc, 5) and $\beta$-DGalf-(1,4)-GlcpNAc, 6. For these isomers, the Nacetylglucosamine residue has a basic substituent that ensures the facile formation of protonated ions. We therefore acquired IR data from the protonated species and the lithium-ion adducts in water/methanol. The mass spectra of the disaccharides revealed signals at $\mathrm{m} / \mathrm{z} 384$ and $\mathrm{m} / \mathrm{z}$ 390 for protonated ions and the lithium-ion adducts, respectively. The CID spectra of the protonated and lithium disaccharide adducts (Figures S6 and S7, respectively) had signatures consistent with the expected fragmentation patterns: a loss of water (at m/z 366 and m/z 372 for the protonated and lithium-ion species). The protonated disaccharides also afforded two intense fragments at $\mathrm{m} / \mathrm{z} 222$ and m/z 204 that correspond to the $\mathrm{Y}$ and $\mathrm{Z}$ fragments after cleavage of the glycosidic bond. The lithium-complexed disaccharides show a small amount of B, $\mathrm{C}, \mathrm{Y}$, and $\mathrm{Z}$ fragments and cross-ring fragments. Overall, MS/MS analysis featured the same fragments for both galactose-containing isomers, highlighting the need for IRMPD analysis.

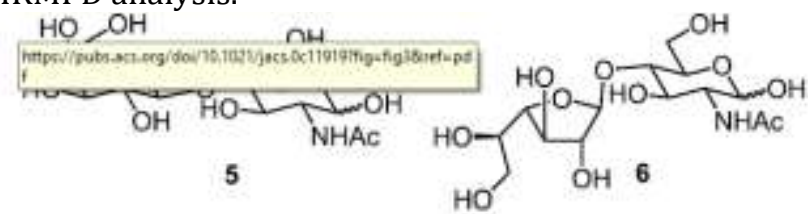

Figure 3. Disaccharides analyzed from the monosacchande IRMPD fingerprints: Galp $\beta(1-4)$ GleNAc 5 and Galf $\beta(1-4)$ GlcNAc 6,

The IRMPD signatures of the protonated galactosecontaining disaccharide adducts were consistent with the ammonium adducts of the monosaccharide standards. First, they show an intense vibrational activity throughout the whole frequency range (Figure 4). The furanose and pyranose forms have similar IR profiles but feature distinctive $\mathrm{O}-\mathrm{H}$ patterns above 3500 $\mathrm{cm}-1$. Compound 6 gives rise to a doublet of $\mathrm{O}-\mathrm{H}$ modes at 3630 and $3660 \mathrm{~cm}-1$. The IRMPD spectrum of $\mathrm{N}$-acetyllactosamine 5 also has a third significant $\mathrm{O}-\mathrm{H}$ mode at $3600 \mathrm{~cm}-1$, which is indicative of galactopyranose (Figure 4). The features of the IRMPD fingerprints of lithium cation adducts in the $[2700,3700] \mathrm{cm}-1$ range align with those observed for the monosaccharide standards (Figure S8). The IR fingerprints of the lithium adducts show significantly less vibrational activity than those of the protonated species; however, a secondary band of lower intensity at $3600 \mathrm{~cm}^{-1}$ is visible in the spectrum of $\mathrm{N}$ acetyllactosamine 5 yet absent from the spectrum of isomer 6. Thus, the galactose ring size between these two compounds can be resolved in both protonated and lithiated species.

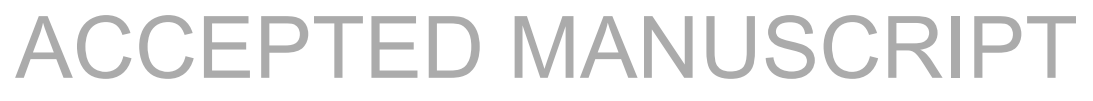




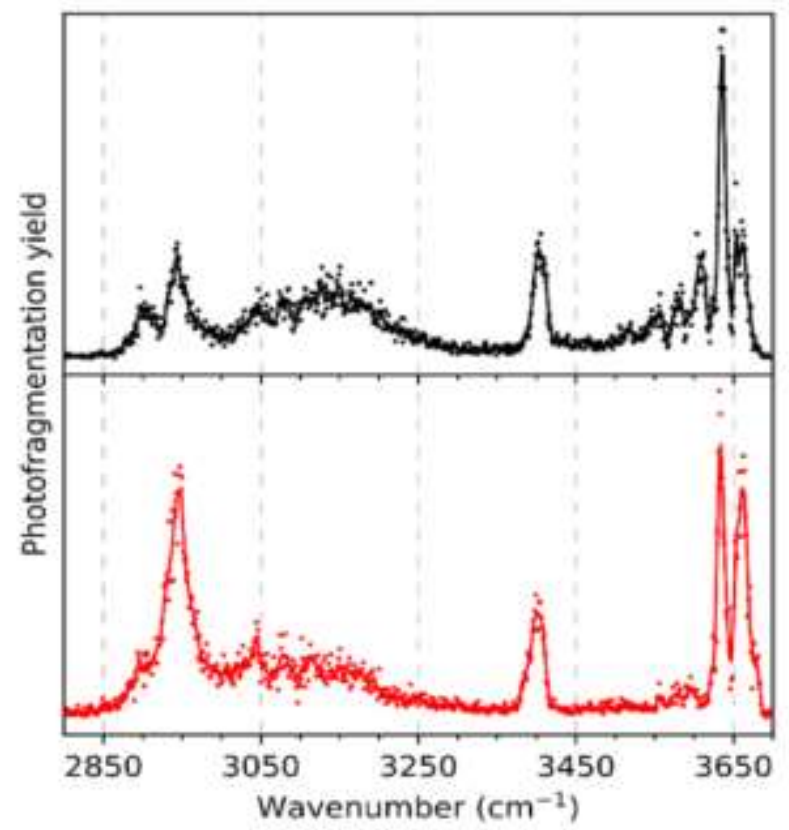

Figure 4. IRMPD spectra of protonated $\beta$-D-Galp-( 1,4$)$-GlcpNAc (5, black) and $\beta$-D-Galf-(1,4)-GlcpNAc $(6$, red).

The disaccharide data above indicate that the protonated species is an excellent reporter of ring size: the overall spectra of the isomers show many different features. Determination of ring size is also possible, albeit with less contrast, using lithium adducts. Thus, MSIR can distinguish galactopyranose- and galactofuranose-containing oligosaccharides.

The relationship between the structure and function of bacterial polysaccharides can be difficult to dissect. Developing analytical methods to discriminate pyranose and furanose building blocks in polysaccharides is critical for sequencing bacterial glycans. For example, the $\mathrm{O}$-antigens of some Klebsiella pneumoniae strains have sequences with both galactofuranose and galactopyranose.22 Because our MS-IR strategy can distinguish ring size and the anomeric configuration, it can aid in polysaccharide analysis. The IRMPD signatures of the $\alpha$ and $\beta$ isomers of methyl galactoside in pyranose and furanose forms were obtained with ammonium and lithium adducts. For ring size determination, ammonium adducts offer a reliable diagnostic. If knowledge of the ring size and the anomeric configuration is required, the IRMPD spectra of $\mathrm{Li}+$ adducts exhibit distinct patterns for all four isomers. In contrast, the spectra of protonated ions did not give rise to diagnostic patterns. Similarly, we collected IRMPD signatures of galactose-containing disaccharides for protonated and $\mathrm{Li}+$ adducts. The galactose residue ring size could be resolved with either adduct.

Our results highlight the power of MS-IR spectroscopy for analyzing glycans. The identification of ring size and anomer demonstrated here is promising for the analysis of oligosaccharides. We anticipate that the proposed MS-IR diagnostic for the presence of galactofuranosyl rings will help determine glycan structures in microbes that range from pathogenic to commensal bacteria, as well as in protozoan and fungal pathogens. Such data can also benchmark computational approaches, which are notoriously less effective for hexofuranose than for hexopyranose rings, as the former has greater conformational flexibility.23,37,38 More broadly, these data highlight the capabilities of IRMPD in developing highresolution carbohydrate sequencing methods, including the analysis of neutral sugars.

\section{ASSOCIATED CONTENT}

* Supporting Information

The Supporting Information is available free of charge at https://pubs.acs.org/doi/10.1021/jacs.0c11919.

Additional figures, experimental procedures, synthesis of small molecules, and MS-IR analyses (PDF)

\section{AUTHOR INFORMATION}

Corresponding Authors

Laura L. Kiessling - Department of Chemistry, Massachusetts Institute of Technology, Cambridge, Massachusetts 02139, United States; orcid.org/0000-0001-6829-1500; Email: kiesslin@mit.edu

Isabelle Compagnon - Univ. Lyon, Université Claude Bernard Lyon 1, F-69622 Villeurbanne, France; orcid.org/0000-0003-2994-3961; Email: isabelle.compagnon@univ-lyon1.fr

Authors

Jordan S. Ho - Department of Chemistry, Massachusetts Institute of Technology, Cambridge, Massachusetts 02139, United States; orcid.org/0000-0001-7355-0431

Amira Gharbi - Univ. Lyon, Université Claude Bernard Lyon 1, F-69622 Villeurbanne, France

Baptiste Schindler - Univ. Lyon, Université Claude Bernard Lyon 1, F-69622 Villeurbanne, France; orcid.org/0000-0002-7376-4154

Oznur Yeni - Univ. Lyon, Université Claude Bernard Lyon 1, F-69622 Villeurbanne, France

Richard Brédy - Univ. Lyon, Université Claude Bernard Lyon 1, F-69622 Villeurbanne, France; orcid.org/00000003-0196-3477

Laurent Legentil - Univ. Rennes, Ecole Nationale Supérieure de Chimie de Rennes, F-35000 Rennes, France; orcid.org/0000-0003-1402-150X

Vincent Ferrières - Univ. Rennes, Ecole Nationale Supérieure de Chimie de Rennes, F-35000 Rennes, France; orcid.org/0000-0002-2780-7774

Complete contact information is available at: https://pubs.acs.org/10.1021/jacs.0c11919

Author Contributions

+J.S.H. and A.G. contributed equally.

Notes

The authors declare no competing financial interest.

\section{ACKNOWLEDGMENTS}

This work was supported by ANR ALGAIMS (grant ANR18- CE29-0006-03 to IC) and the National Institute of Allergy and Infectious Disease (Al-126592 to LLK) and 
the NIH Common Fund (U01GM125288 to LLK). We thank Katherine Taylor for helpful discussions.

\section{REFERENCES}

(1) Wuhrer, M. Glycomics Using Mass Spectrometry. Glycoconjugate J. 2013, 30 (1), 11-22.

(2) Leymarie, N.; Zaia, J. Effective Use of Mass Spectrometry for Glycan and Glycopeptide Structural Analysis. Anal. Chem. 2012, 84 (7), 3040-3048.

(3) Peter-Katalinić, J. Mass Spectrometry and Glycomics. Supramolecular Structure and Function 9 2007, 14 (4), 89-102.

(4) Herget, S.; Toukach, P. V.; Ranzinger, R.; Hull, W. E.; Knirel, Y. A.; Von Der Lieth, C. W. Statistical Analysis of the Bacterial

Carbohydrate Structure Data Base (BCSDB): Characteristics and Diversity of Bacterial Carbohydrates in Comparison with Mammalian Glycans. BMC Struct. Biol. 2008, 8, 35.

(5) Adibekian, A.; Stallforth, P.; Hecht, M. L.; Werz, D. B.; Gagneux, P.; Seeberger, P. H. Comparative Bioinformatics Analysis of the Mammalian and Bacterial Glycomes. Chem. Sci. 2011, 2 (2), 337-344.

(6) Pabst, M.; Altmann, F. Glycan Analysis by Modern Instrumental Methods. Proteomics 2011, 11 (4), 631-643.

(7) Hart, G. W.; Copeland, R. J. Glycomics Hits the Big Time. Cell 2010, 143 (5), 672-676.

(8) Gray, C. J.; Migas, L. G.; Barran, P. E.; Pagel, K.; Seeberger, P. H.; Eyers, C. E.; Boons, G.-J.; Pohl, N. L. B.; Compagnon, I.; Widmalm, G.; Flitsch, S. L. Advancing Solutions to the Carbohydrate Sequencing Challenge. J. Am. Chem. Soc. 2019, 141 (37), 14463-14479.

(9) Cummings, R. D.; Pierce, J. M. The Challenge and Promise of Glycomics. Chem. Biol. 2014, 21 (1), 1-15.

(10) Rillahan, C. D.; Paulson, J. C. Glycan Microarrays for Decoding the Glycome. Annu. Rev. Biochem. 2011, 80, 797-823.

(11) Song, X.; Lasanajak, Y.; Xia, B.; Heimburg-Molinaro, J.; Rhea, J. M.; Ju, H.; Zhao, C.; Molinaro, R. J.; Cummings, R. D.; Smith, D. F. Shotgun Glycomics: A Microarray Strategy for Functional Glycomics. Nat. Methods 2011, 8 (1), 85-90.

(12) Both, P.; Green, A. P.; Gray, C. J.; Sardzík, R.; Voglmeir, J.; Fontana, C.; Austeri, M.; Rejzek, M.; Richardson, D.; Field, R. A.; Widmalm, G.; Flitsch, S. L.; Eyers, C. E. Discrimination of Epimeric Glycans and Glycopeptides Using IM-MS and Its Potential for Carbohydrate Sequencing. Nat. Chem. 2014, 6 (1), 65-74.

(13) Gray, C. J.; Thomas, B.; Upton, R.; Migas, L. G.; Eyers, C. E.; Barran, P. E.; Flitsch, S. L. Applications of Ion Mobility Mass Spectrometry for High Throughput, High Resolution Glycan Analysis. Biochim. Biophys. Acta, Gen. Subj. 2016, 1860 (8), 1688-1709.

(14) Deng, L.; Ibrahim, Y. M.; Baker, E. S.; Aly, N. A.; Hamid, A. M.; Zhang, X.; Zheng, X.; Garimella, S. V. B.; Webb, I. K.; Prost, S. A.; Sandoval, J. A.; Norheim, R. V.; Anderson, G. A.; Tolmachev, A. V.; Smith, R. D. Ion Mobility Separations of Isomers Based upon Long Path Length Structures for Lossless Ion Manipulations Combined with Mass Spectrometry. ChemistrySelect 2016, 1 (10), 2396-2399.

(15) Ujma, J.; Ropartz, D.; Giles, K.; Richardson, K.; Langridge, D.; Wildgoose, J.; Green, M.; Pringle, S. Cyclic Ion Mobility Mass Spectrometry Distinguishes Anomers and Open-Ring Forms of Pentasaccharides. J. Am. Soc. Mass Spectrom. 2019, 30 (6), 1028-1037.

(16) Gray, C. J.; Schindler, B.; Migas, L. G.; Pičmanová, M.; Allouche, A. R.; Green, A. P.; Mandal, S.; Motawia, M. S.; SánchezPérez, R.; Bjarnholt, N.; Møller, B. L.; Rijs, A. M.; Barran, P. E.; Compagnon, I.; Eyers, C. E.; Flitsch, S. L. Bottom-Up Elucidation of Glycosidic Bond Stereochemistry. Anal. Chem. 2017, 89 (8), 4540-4549.
(17) Ben Faleh, A.; Warnke, S.; Rizzo, T. R. Combining UltrahighResolution Ion-Mobility Spectrometry with Cryogenic Infrared Spectroscopy for the Analysis of Glycan Mixtures. Anal. Chem. 2019, 91 (7), 4876-4882.

(18) Warnke, S.; Ben Faleh, A.; Scutelnic, V.; Rizzo, T. R. Separation and Identification of Glycan Anomers Using Ultrahigh-Resolution Ion-Mobility Spectrometry and Cryogenic Ion Spectroscopy. J. Am. Soc. Mass Spectrom. 2019, 30 (11), 2204-2211.

(19) Mucha, E.; González Flórez, A. I.; Marianski, M.; Thomas, D. A.; Hoffmann, W.; Struwe, W. B.; Hahm, H. S.; Gewinner, S.; Schöllkopf, W.; Seeberger, P. H.; von Helden, G.; Pagel, K. Glycan Fingerprinting via Cold-Ion Infrared Spectroscopy. Angew. Chem., Int. Ed. 2017, 56 (37), 11248-11251.

(20) Richards, M. R.; Lowary, T. L. Chemistry and Biology of Galactofuranose-Containing Polysaccharides. ChemBioChem 2009, 10 (12), 1920-1938.

(21) Peltier, P.; Euzen, R.; Daniellou, R.; Nugier-Chauvin, C.; Ferrieres, V. Recent Knowledge and Innovations Related to Hexofuranosides: Structure, Synthesis and Applications. Carbohydr. Res. 2008, 343 (12), 1897-1923.

(22) Taniguchi, T.; Nakano, K.; Baba, R.; Monde, K. Analysis of Configuration and Conformation of Furanose Ring in Carbohydrate and Nucleoside by Vibrational Circular Dichroism. Org. Lett. 2017, 19 (2), 404-407.

(23) Richards, M. R.; Bai, Y.; Lowary, T. L. Comparison between DFT- and NMR-Based Conformational Analysis of Methyl Galactofuranosides. Carbohydr. Res. 2013, 374, 103-114.

(24) Cocinero, E. J.; Stanca-Kaposta, E. C.; Dethlefsen, M.; Liu, B.; Gamblin, D. P.; Davis, B. G.; Simons, J. P. Hydration of Sugars in the Gas Phase: Regioselectivity and Conformational Choice in N-Acetyl Glucosamine and Glucose. Chem. - Eur. J. 2009, 15 (48), 13427-13434.

(25) Écija, P.; Uriarte, I.; Spada, L.; Davis, B. G.; Caminati, W.; Basterretxea, F. J.; Lesarri, A.; Cocinero, E. J. Furanosic Forms of Sugars: Conformational Equilibrium of Methyl $\beta$-d-Ribofuranoside. Chem. Commun. 2016, 52 (37), 6241-6244.

(26) Schindler, B.; Barnes, L.; Renois, G.; Gray, C.; Chambert, S.; Fort, S.; Flitsch, S.; Loison, C.; Allouche, A. R.; Compagnon, I. Anomeric Memory of the Glycosidic Bond upon Fragmentation and Its Consequences for Carbohydrate Sequencing. Nat. Commun. 2017, 8, 973.

(27) Polfer, N. C.; Oomens, J. Vibrational Spectroscopy of Bare and Solvated Ionic Complexes of Biological Relevance. Mass Spectrom. Rev. 2009, 28 (3), 468-494.

(28) Tan, Y.; Zhao, N.; Liu, J.; Li, P.; Stedwell, C. N.; Yu, L.; Polfer, N. C. Vibrational Signatures of Isomeric Lithiated N-AcetylDHexosamines by Gas-Phase Infrared Multiple-Photon Dissociation (IRMPD) Spectroscopy. J. Am. Soc. Mass Spectrom. 2017, 28 (3), 539-550.

(29) Barnes, L.; Schindler, B.; Chambert, S.; Allouche, A.-R.; Compagnon, I. Conformational Preferences of Protonated NAcetylated Hexosamines Probed by InfraRed Multiple Photon Dissociation (IRMPD) Spectroscopy and Ab Initio Calculations. Int. J. Mass Spectrom. 2017, 421, 116-123.

(30) Cagmat, E. B.; Szczepanski, J.; Pearson, W. L.; Powell, D. H.; Eyler, J. R.; Polfer, N. C. Vibrational Signatures of Metal-Chelated Monosaccharide Epimers: Gas-Phase Infrared Spectroscopy of Rb+-Tagged Glucuronic and Iduronic Acid. Phys. Chem. Chem. Phys. 2010, 12, 3474-3479.

(31) Schindler, B.; Renois-Predelus, G.; Bagdadi, N.; Melizi, S.; Barnes, L.; Chambert, S.; Allouche, A.-R.; Compagnon, I. MS/IR, a New MS-Based Hyphenated Method for Analysis of Hexuronic Acid Epimers in Glycosaminoglycans. Glycoconjugate J. 2017, 34 (3), 421-425.

(32) Depraz Depland, A.; Renois-Predelus, G.; Schindler, B.; Compagnon, I. Identification of Sialic Acid Linkage Isomers in 
Glycans Using Coupled InfraRed Multiple Photon Dissociation (IRMPD) Spectroscopy and Mass Spectrometry. Int. J. Mass Spectrom. 2018, 434, 65-69.

(33) Schindler, B.; Barnes, L.; Gray, C. J.; Chambert, S.; Flitsch, S. L.; Oomens, J.; Daniel, R.; Allouche, A. R.; Compagnon, I. IRMPD Spectroscopy Sheds New (Infrared) Light on the Sulfate Pattern of Carbohydrates. J. Phys. Chem. A 2017, 121 (10), 2114-2120.

(34) Masellis, C.; Khanal, N.; Kamrath, M. Z.; Clemmer, D. E.; Rizzo, T. R. Cryogenic Vibrational Spectroscopy Provides Unique Fingerprints for Glycan Identification. J. Am. Soc. Mass Spectrom. 2017, 28 (10), 2217-2222.

(35) Kailemia, M. J.; Ruhaak, L. R.; Lebrilla, C. B.; Amster, I. J. Oligosaccharide Analysis by Mass Spectrometry: A Review of Recent Developments. Anal. Chem. 2014, 86 (1), 196-212.

(36) Hernandez, O.; Isenberg, S.; Steinmetz, V.; Glish, G. L.; Maitre, P. Probing Mobility-Selected Saccharide Isomers: Selective Ion-Molecule Reactions and Wavelength-Specific IR Activation. J. Phys. Chem. A 2015, 119, 6057-6064.

(37) Schindler, B.; Legentil, L.; Allouche, A.-R.; Ferrières, V.; Compagnon, I. Spectroscopic Diagnostic for the Ring-Size of Carbohydrates in the Gas Phase: Furanose and Pyranose Forms of GalNAc. Phys. Chem. Chem. Phys. 2019, 21 (23), 12460-12467.

(38) Calabrese, C.; Uriarte, I.; Insausti, A.; Vallejo-López, M.; Basterretxea, F. J.; Cochrane, S. A.; Davis, B. G.; Corzana, F.; Cocinero, E. J. Observation of the Unbiased Conformers of Putative DNA-Scaffold Ribosugars. ACS Cent. Sci. 2020, 6 (2), 293-303. 